14,13

\title{
Структурный переход в пленках триацетата целлюлозы
}

\author{
(ㄱ Д.В. Новиков \\ Санкт-Петербургский государственный лесотехнический университет им. С.М. Кирова, \\ Санкт-Петербург, Россия \\ E-mail: dvnovikov65@mail.ru
}

Поступила в Редакцию 21 октября 2021 г.

В окончательной редакции 21 октября 2021 г.

Принята к публикайции 25 октября 2021 г.

По данным электронной микроскопии проведен сравнительный анализ топологической структуры поверхности двух образцов пленок триацетата целлюлозы (СТА). Образцы были получены из растворов СТА без использования (образец № 1) и с применением малой добавки фторида натрия, понижающего вязкость раствора (образец № 2). Показано, что в образце № 1 узлами сетки зацеплений макромолекул являются периодически чередующиеся области локального ориентационного порядка - микродомены среднего размера $d \sim 18 \mathrm{~nm}$. В образце № 2 за счет переупаковки микродоменов на масштабе $R>d$ формируется однородно неупорядоченный фрактальный кластер мезофазы СТА. Фрактализация поверхности и рост структурной анизотропии согласуются с падением вязкости раствора и объясняют изменение деформационных свойств образца № 2 по сравнению с № 1.

Ключевые слова: полимерные пленки, электронная микроскопия, микродомены, мезофаза, структурный переход, фрактальные кластеры.

DOI: 10.21883/FTT.2022.02.51941.224

\section{1. Введение}

Образцы триацетата целлюлозы (СТА) с содержанием связанной уксусной кислоты $\alpha=60.0-61.9 \%$ относятся к полимерам с жесткими макромолекулами [1], способными к образованию в растворе анизотропных агрегатов [2].

Известно, что исходная массовая концентрация $c$ полимера определяет характер агрегации макромолекул СТА в растворе [2], на межфазной границе раствортвердое тело [3] и при пленкообразовании [4]. Образование агрегатов частиц в растворах различных образцов СТА фиксируется методом ИК-спектроскопии [2,3]: при $c>6 \mathrm{wt} \%$ число анизотропных кластеров резко возрастает, а при $c>10 \mathrm{wt} \%$ формируется лиотропное жидкокристаллическое состояние [5].

В работе [4] с применением метода электронной микроскопии (ЕМ) обоснована микродоменная структура пленок, полученных из растворов СТА ( $\alpha=61.9 \%)$. Под микродоменами понимались локальные области максимального размера $d \sim 30 \mathrm{~nm}$, которым должна отвечать нематическая упорядоченность сегментов макромолекул [6]. Было показано, что с ростом концентрации $c$ полимера в растворе увеличивается плотность упаковки микродоменов в пленке. В серии образцов пленок, сформированных из растворов различной концентрации, был обнаружен структурный переход по шкале параметра $c$ вблизи значения $c \sim 9 \mathrm{wt} \%$. Этот переход указывает на возникновение однородного бесконечного кластера мезофазы СТА и связан с распространением корреляций типа плотность-плотность на расстояние, существенно превышающее $d$.
Поскольку характер агрегации макромолекул в растворе зависит также от природы (качества) растворителя [2,7], существует возможность регулирования анизотропной надмолекулярной структуры СТА [8] в пленках путем введения в пленкообразующий раствор модифицирующих добавок $[9,10]$. Например, усиление специфической сольватации карбонильных групп ацетильных заместителей СТА молекулами протонодонорных растворителей при введении в раствор небольших количеств (0.001-0.1 wt.\% от СТА) некоторых неорганических солей, в частности фторида натрия, приводит к заметному снижению динамической вязкости $[2,11]$. Падение вязкости является признаком упорядочения кластерной структуры раствора и согласуется с изменением деформационных свойств получаемых пленок увеличением относительного удлинения при разрыве и уменьшением термостатной усадки [11]. Однако в работе [11] отсутствуют данные структурного анализа, объясняющие изменения ряда физико-механических характеристик пленок.

В настоящей работе проведен сравнительный анализ топологической структуры поверхности двух образцов пленок СТА, полученных из растворов полимера без использования и с применением малой добавки фторида натрия. Для структурного анализа поверхности в субмикронном диапазоне масштаба использована оригинальная ЕМ-методика декорирования золотом электрически активной реплики из аморфного германия [12]. По данным ЕМ рассчитаны индикатрисы плотности распределения декорирующих наночастиц золота, корреляционные функции типа плотность-плотность и параметры надмолекулярной структуры СТА на поверх- 
ности пленок. Цель работы - объяснение взаимосвязи „состав-структура-свойства“ на основе микродоменной (кластерной) модели строения пленок СТА.

\section{2. Объекты и методы исследования}

В работе использовался промышленный частично гидролизованный СТА с содержанием связанной уксусной кислоты $\alpha=60.1 \%$ и степенью полимеризации 300 . Рентгеноаморфные [4] пленки толщиной $\sim 130 \mu \mathrm{m}$ формировались из $10 \mathrm{wt} \%$ растворов СТА в смеси метиленхлорид-этанол $(9: 1)$ на зеркальном стекле при $298 \mathrm{~K}$ без использования (образец № 1) и с применением малой добавки (0.005 wt.\% от СТА) фторида натрия (образец № 2). Указанное количество модификатора соответствует минимуму динамической вязкости пленкообразующего $10 \mathrm{wt} . \%$ раствора полимера [11].

Концентрация $c=10 \mathrm{wt} . \%$ для использованного образца СТА несколько превышает пороговое значение $c^{*}=9.7$ wt.\% [2], соответствующее формированию в растворе непрерывной сетки зацеплений макромолекул [7]. Согласно результатам работы [4] выбранный концентрационный режим пленкообразования должен приводить к возникновению в пленках бесконечного кластера мезофазы СТА.

C „воздушной“ поверхности полимерных пленок формировались двухслойные германиево-угольные реплики. Для получения реплик на поверхность образцов проводилось последовательное вакуумное термическое напыление аморфного слоя особо чистого германия толщиной $5 \mathrm{~nm}$ и опорного слоя углерода. В ходе отрыва двухслойной реплики от пленкиподложки слой германия приобретал электрический заряд, пространственная локализация которого соответствовала характеру распределения электронодонорных ацетильных заместителей СТА на поверхности образца [12]. Электрически активные реплики декорировались золотом [13] путем вакуумного термического напыления металла до эффективной толщины слоя $0.4 \mathrm{~nm}$ [14]. Во избежание фотоэмиссии электронов и релаксации электрического заряда получение реплик и их декорирование золотом производилось в темноте.

Полученные в просвечивающем электронном микроскопе изображения декорированных золотом германиево-угольных реплик отображают распределение плотности упаковки макромолекул СТА на поверхности образцов (рис. 1). Важно отметить, что в данном случае наиболее вероятное расстояние $r$ между наночастицами золота составляет $6 \mathrm{~nm}$. Это значительно повышает разрешающую способность описанной выше ЕМ-методики по сравнению с использованной в работах $[4,14]$ методикой декорирования золотом „химических меток“ хемосорбированного молекулярного брома, поскольку в последнем случае величина $r$ существенно выше.

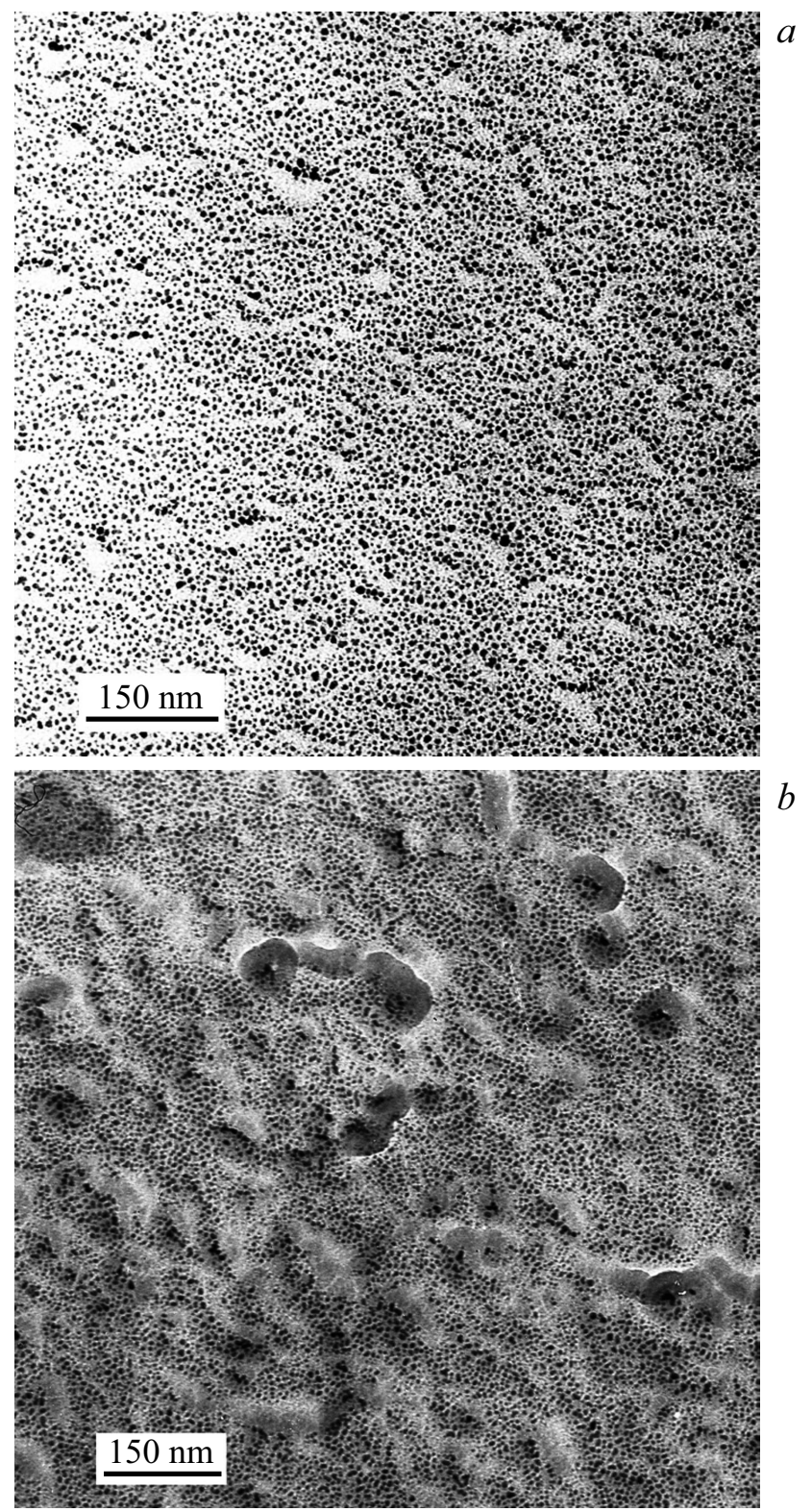

Рис. 1. Электронные микрофотографии декорированных золотом германиево-угольных реплик с поверхности пленок СТА: образец № $1(a)$, образец № $2(b)$.

Изучение пространственных корреляций типа плотность-плотность на поверхности образцов проводилось с использованием так называемых „крупнозернистых“ радиальных функций $g(R)$ распределения декорирующих наночастиц золота. Для получения этих функций использовалась компьютерная процедура пошагового сканирования плотности распределения частиц на двумерных изображениях поверхности с шагом $\delta$, соответствующим величине $r$ [14]. Корреляционная длина $\xi$ определялась по положению особых точек функций $g(R)$. Индикатрисы плотности $\rho$ распределения наночастиц золота рассчитывались при усреднении по прямоугольникам $2 r \times \xi$ 
с центром в частицах и изменении угла $\theta$ ориентации прямоугольников [14].

\section{3. Результаты и их обсуждение}

На электронных микрофотографиях декорированных реплик с поверхности образцов пленок (рис. 1) наночастицы золота локализованы неоднородно: наряду с областями достаточно плотного расположения декорирующих частиц имеются свободные от золота области. Непрерывная квазирешетка наночастиц соответствует бесконечному кластеру плотноупакованных макромолекул СТА (мезофазе полимера). Степень $\Omega$ заполнения поверхности кластером [15] составляет 0.64 и 0.54 для образцов № 1 и 2 соответственно. Уменьшение величины $\Omega$ при переходе от образца № 1 к образцу № 2 сопровождается уплотнением узлов квазирешетки, что отображается небольшим уширением первого пика функции $g(R)$ радиального распределения декорирующих наночастиц (рис. 2). При этом среднее координационное число казирешетки [15] возрастает от 4 до 6.
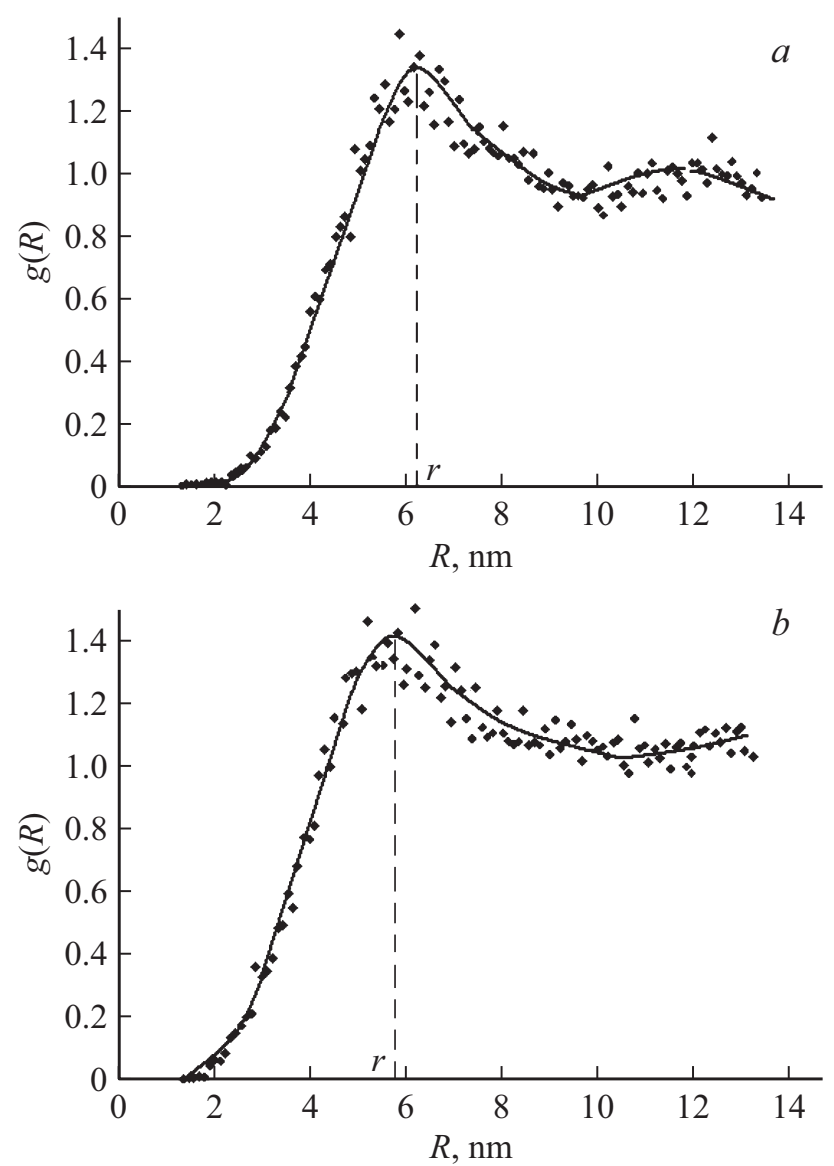

Рис. 2. Радиальные функции $g(R)$ распределения наночастиц золота на декорированных репликах с поверхности пленок СТА: образец № $1(a)$, образец № $2(b)$. Шаг сканирования изображения поверхности $\delta=1 \mathrm{~nm}$.
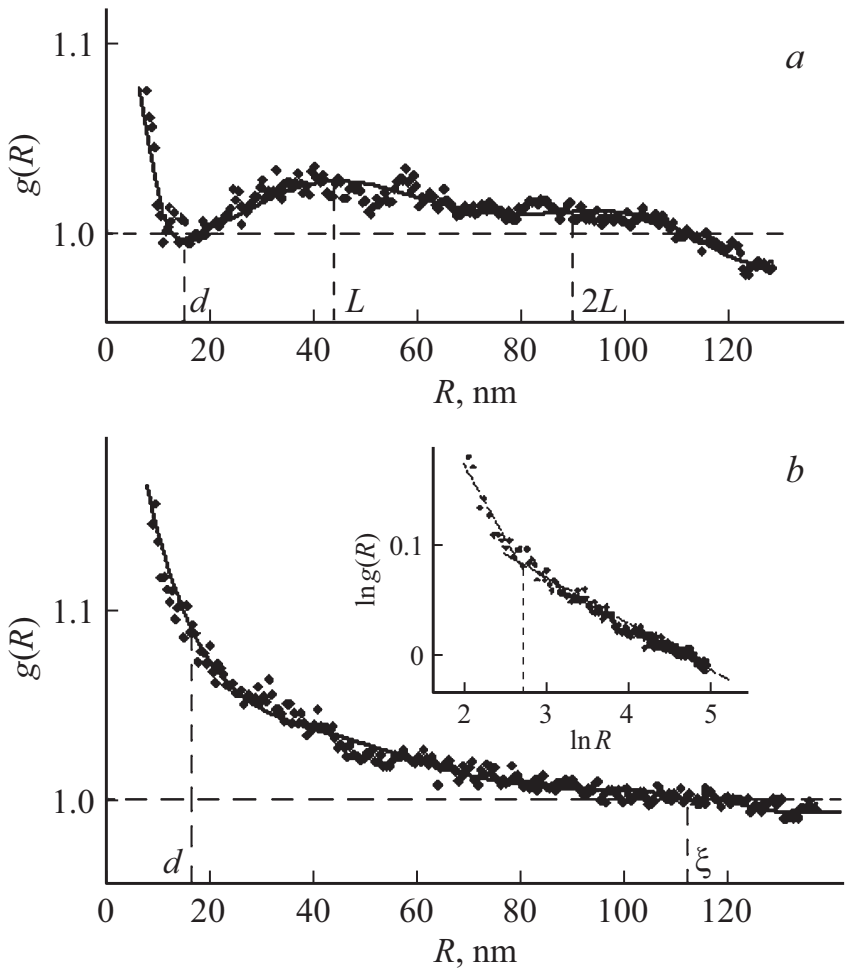

Рис. 3. „Крупнозернистые“ радиальные функции $g(R)$ распределения наночастиц золота на декорированных репликах с поверхности пленок СТА (корреляционные функции $g(R)$ типа плотность-плотность): образец № $1(a)$, образец № $2(b)$. Шаг сканирования изображения поверхности $\delta=6 \mathrm{~nm}$. На вставке: функция $g(R)$ в двойных логарифмических координатах для образца № 2 .

Трансформация квазирешетки декорирующих наночастиц сопутствует изменению характера пространственных корреляций типа плотность-плотность в кластере мезофазы СТА. „Крупнозернистые“ радиальные функции $g(R)$ распределения декорирующих наночастиц (рис. 3 ) демонстрируют принципиально различное поведение с ростом величины масштаба $R$.

В образце № 1 корреляционная функция $g(R)$ типа плотность-плотность испытывает периодические осцилляции с периодом $L \sim 42 \mathrm{~nm}$ вблизи значения $g(R)=1$ (рис. 3,a), что свидетельствует о периодическинеоднородной топологической структуре кластера мезофазы СТА. Пространственные корреляции распространяются на расстояние $\xi=2 L$, где $\xi-$ корреляционная длина. Вид функции $g(R)$ согласуется с микродоменной моделью СТА для периодически чередующихся частиц среднего размера $d \sim 18 \mathrm{~nm}$ и фрактальной размерности $[16] \quad D=1.80 \pm 0.05$, определяемой при аппроксимации начального участка графика функции $g(R)$ степенной зависимостью $g(R) \propto R^{D-2}$. Параметры $d$ и $D$ микродоменов соответствуют данным малоуглового рассеяния рентгеновских лучей (SAXS) [4]. Компьютерная обработка угловой зависимости интенсивности $I(\theta)$ рассеяния в области $8^{\prime}<2 \theta<15^{\prime}$, в том числе 
с применением процедуры Гинье, приводит к значениям параметров $d=24 \mathrm{~nm}$ и $D=1.7 \pm 0.1$ для рассеивающих структонов [4,17]. Следует отметить, что на рентгенограмме SAXS образца № 1 не проявляется дискретный рефлекс, отвечающий периоду $L \sim 42 \mathrm{~nm}$ чередования микродоменов, вследствие малой рассеивающей способности полимерной пленки [4,17].

В отличие от образца № 1 в образце № 2 ,крупнозернистая“" корреляционная функция $g(R)$ с ростом величины масштаба $R$ спадает по степенному закону (рис. $3, b$ ): $g(R) \propto R^{D-2}$, причем, значение фрактальной размерности $D$ зависит от $R$. Построение функции $g(R)$ в двойных логарифмических координатах (рис. $3, b$, вставка) показывает, что при $R<18 \mathrm{~nm}$ величина $D=1.84 \pm 0.02$ соответствует микродоменам, а при $R>18 \mathrm{~nm}$ фрактальная размерность $D=1.96 \pm 0.01$ характеризует тело кластера мезофазы СТА. Отметим, что средний размер $d \sim 18 \mathrm{~nm}$ микродоменов в двух изученных образцах пленок сохраняется неизменным (рис. $3, a, b)$ и согласуется с величиной термодинамического сегмента для различных эфиров целлюлозы [1].

Таким образом, при сравнении образцов № 1 и 2 на масштабе $R>d$ наблюдается структурный переход, связанный с переупаковкой упорядоченных микродоменов и формированием тела однородно неупорядоченного фрактального кластера мезофазы СТА.
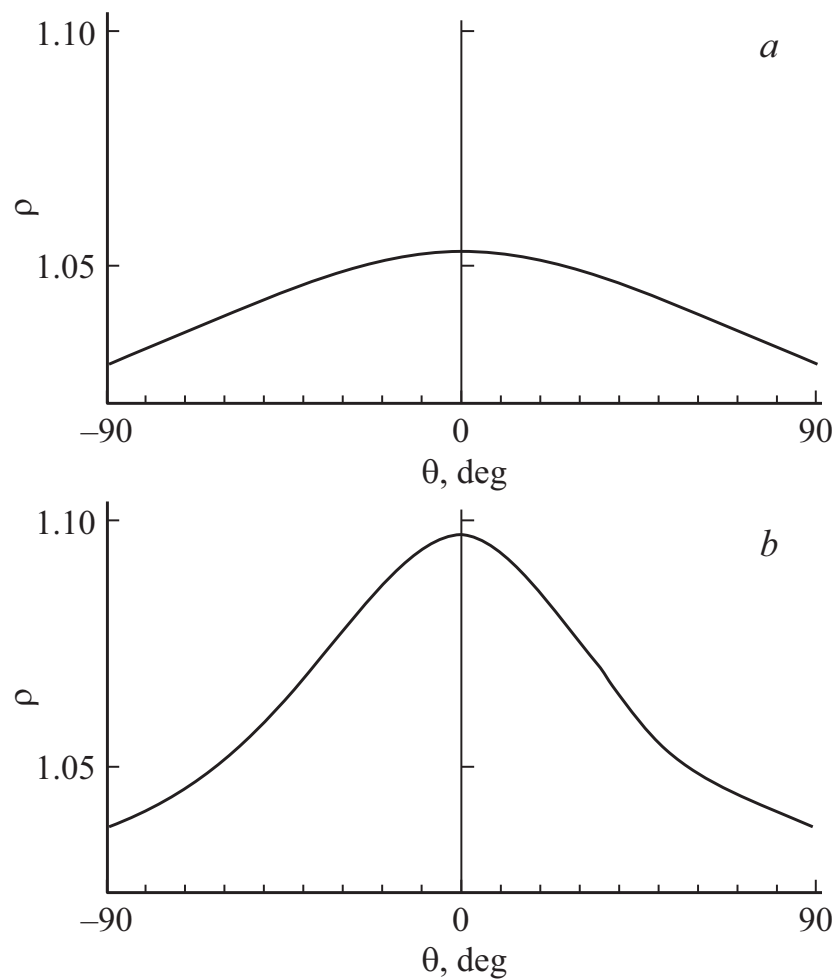

Рис. 4. Индикатрисы относительной (по отношению к средней по поверхности) плотности $\rho$ распределения наночастиц золота на декорированных репликах с поверхности пленок СТА: образец № $1(a)$, образец № $2(b)$. Ось ординат $(\theta=0$ градусов $)$ соответствует оси текстуры - направлению с максимальным значением $\rho$.
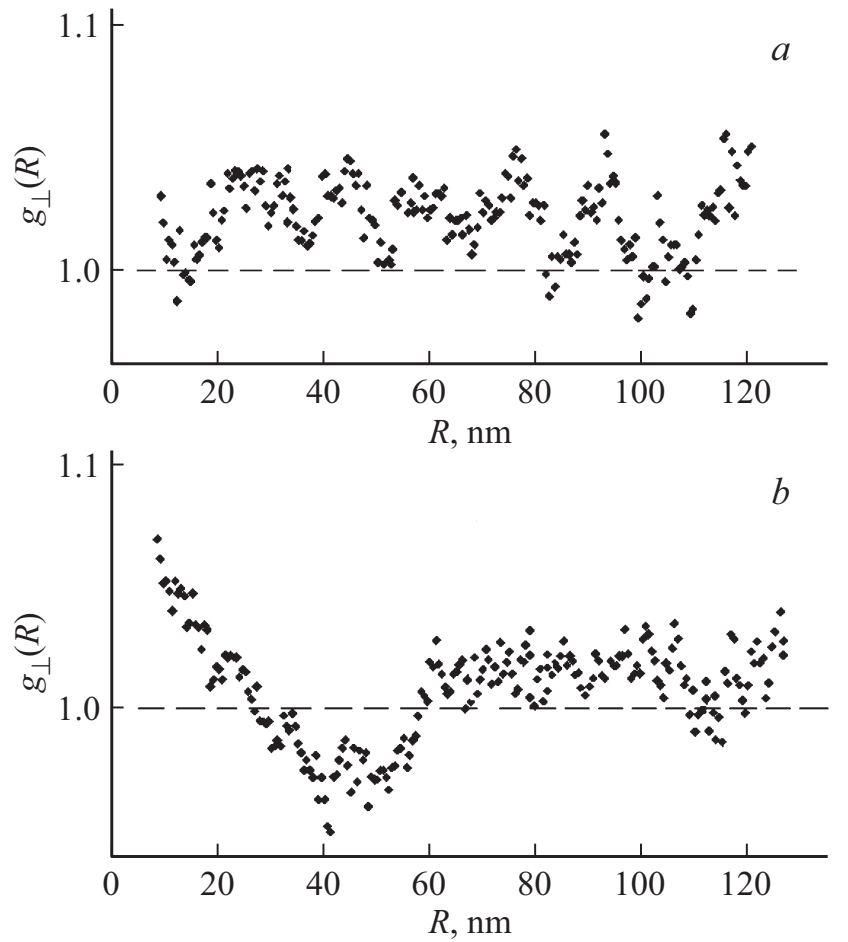

Рис. 5. Радиальные функции распределения плотности, построенные поперек оси аксиальной текстуры на поверхности пленок СТА: образец № $1(a)$, образец № $2(b)$. Шаг сканирования изображения поверхности $\delta=1 \mathrm{~nm}$.

На рис. 4 представлены индикатрисы относительной локальной плотности $\rho$ распределения наночастиц золота на поверхности образцов. Полученные угловые зависимости $\rho(\theta)$ свидетельствуют об аксиальной текстуре поверхности пленок. Наличие аксиальной текстуры может быть связано как с ориентационными эффектами при формовании пленок [12], так и с образованием мезофазы. При переходе от образца № 1 к образцу № 2 анизотропия плотности возрастает, причем отличие в плотности вдоль и поперек оси текстуры увеличивается более чем в два раза, достигая 5\% для образца № 2 (рис. 4, $b$ ).

На рис. 5 приведены корреляционные функции $g_{\perp}(R)$, рассчитанные поперек оси текстуры исследуемых образцов. В образце № 1 в направлении, перпендикулярном оси текстуры, наблюдаются периодические осцилляции плотности с периодом $\sim 18 \mathrm{~nm}$ (рис. 5, $a$ ). Корреляции плотность-плотность распространяются на расстояние более $120 \mathrm{~nm}$, не затухая при этом на всем изученном масштабном интервале. Важно отметить, что по данным SAXS [18] для пленок CTA, прогретых при $453-483 \mathrm{~K}$, в области углов рассеяния $2 \theta=18-24^{\prime}$ имеются плато или перегиб, соответствующие большим периодам $\sim 15-21 \mathrm{~nm}$. Такая особенность рентгенограмм является следствием процессов термической деструкции и кристаллизации СТА [18]. Таким образом, прослеживается генетическая связь между одномерной периодич- 
ностью в структуре кластера мезофазы образца № 1 и выявляемыми методом SAXS [18] большими периодами в пленках СТА, подвергнутых термообработке.

В образце № 2 по сравнению с № 1 отсутствуют периодические осцилляции плотности поперек оси текстуры (рис. $5, b$ ), что свидетельствует об относительном разупорядочении кластерной структуры СТА.

\section{4. Заключение}

Использование малых количеств модификаторов, понижающих вязкость концентрированных растворов жесткоцепных полимеров, позволяет изменять топологическую структуру кластера мезофазы в получаемых пленках. К таким модификаторам для СТА относятся некоторые неорганические соли, например, фторид натрия. Эти соли влияют на сольватацию растворителем функциональных групп полимера и тем самым предопределяют характер агрегации макромолекул [2].

Между двумя образцами пленок СТА, полученных в одних условиях из растворов полимера без использования и с применением малой добавки фторида натрия, обнаруживается структурный переход типа порядокбеспорядок. Этот переход связан с переупаковкой упорядоченных микродоменов, являющихся узлами сетки зацеплений макромолекул в теле кластера мезофазы СТА. При этом периодически-неоднородный кластер трансформируется в однородно неупорядоченный, приобретая фрактальные свойства, увеличивая свою локальную плотность и анизотропию. Такая трансформация объясняет изменение деформационных свойств пленок: увеличение на $30 \%$ относительного удлинения при разрыве и уменьшение в два раза термостатной усадки [11].

\section{Конфликт интересов}

Автор заявляет об отсутствии конфликта интересов.

\section{Список литературы}

[1] Р.Г. Жбанков, П.В. Козлов. Физика целлюлозы и ее производных. Наука и техника, Минск (1983). 296 с.

[2] А.Н. Красовский, Д.Н. Поляков, С.С. Мнацаканов. Высокомолекуляр. соединения 37А, 1551 (1995).

[3] А.Н. Красовский, Д.Н. Поляков, В.Г. Баранов, С.С. Мнацаканов, А.В. Варламов. Высокомолекуляр. соединения 33А, 1228 (1991).

[4] Д.В. Новиков, А.Н. Красовский, С.С. Мнацаканов. ФТТ 54, 382 (2012).

[5] Жидкокристаллические полимеры / Под ред. Н.А. Платэ. Наука, М. (1988). 500 с.

[6] Г.М. Бартенев, С.Я. Френкель. Физика полимеров. Химия, Л. (1990). $432 \mathrm{c}$.

[7] В.Н. Цветков, В.Э. Эскин, С.Я. Френкель. Структура макромолекул в растворах. Наука, М. (1964). 719 с.

[8] О.А. Ханчич. Анизотропные структуры в полимерах и их изучение методом малоуглового рассеяния поляризованного света. Изд-во МТИ, М. (2014). С. 9.
[9] Д.В. Новиков, А.В. Варламов. Коллоид. журн. 59, 355 (1997).

[10] А.М. Бочек, И.В. Серов, И.Л. Шевчук, В.К. Лаврентьев, Е.Н. Попова, Е.Н. Власова, Б.З. Волчек, Е.В. Юдин. ЖПХ 93, 564 (2020).

[11] И.В. Сидорова. Автореф. канд. дис. Институт киноинженеров, СПб (1992). 24 с.

[12] Д.В. Новиков, А.В. Варламов, С.С. Мнацаканов, Е.Ф. Панарин. ДАН СССР 318, 1406 (1991).

[13] Г.И. Дистлер, В.П. Власов, Ю.М. Герасимов. Декорирование поверхности твердых тел. Наука, М. (1976). 111 с

[14] Д.В. Новиков. ФТТ 63, 146 (2021).

[15] Д.В. Новиков, А.В. Варламов. Поверхность 6, 117 (1992).

[16] Е. Федер. Фракталы / Пер. с англ. Ю.А. Данилова, А.М. Шукурова. Мир, М. (1991). 254 с. [J. Feder. Fractals. Plenum Press, N.Y., London (1988). 260 p.].

[17] Д.В. Новиков. Автореф. докт. дис. СПбГТИ, СПб (2009). $10 \mathrm{c}$.

[18] Ш. Туйчиев, Н.С. Султанов, Д. Рашидов, Е.Т. Магдалев, Б.М. Гинзбург. Высокомолекуляр. соединения 18А, 1498 (1976).

Редактор Д.В. Жуманов 